\title{
Seroprevalence and Molecular Identification of Brucella spp. in Bovines in Pakistan-Investigating Association With Risk Factors Using Machine Learning
}

\section{OPEN ACCESS}

Edited by:

Srinand Sreevatsan,

Michigan State University,

United States

Reviewed by:

George Omondi Paul,

University of Minnesota, United States

László Ózsvári,

University of Veterinary Medicine

Budapest, Hungary

*Correspondence:

Hosny El-Adawy

hosny.eladawy@fli.de

Specialty section:

This article was submitted to

Veterinary Epidemiology and

Economics,

a section of the journal

Frontiers in Veterinary Science

Received: 24 August 2020

Accepted: 29 October 2020

Published: 02 December 2020

Citation:

Khan AU, Melzer F, Hendam A, Sayour AE, Khan I, Elschner MC,

Younus M, Ehtisham-ul-Haque $S$,

Waheed U, Farooq M, Ali $S$,

Neubauer $\mathrm{H}$ and El-Adawy H (2020)

Seroprevalence and Molecular

Identification of Brucella spp. in

Bovines in Pakistan-Investigating

Association With Risk Factors Using

Machine Learning.

Front. Vet. Sci. 7:594498.

doi: 10.3389/fvets.2020.594498

\begin{abstract}
Aman Ullah Khan ${ }^{1,2}$, Falk Melzer ${ }^{1}$, Ashraf Hendam ${ }^{3}$, Ashraf E. Sayour ${ }^{4}$, lahtasham Khan ${ }^{5}$, Mandy C. Elschner ${ }^{1}$, Muhammad Younus ${ }^{6}$, Syed Ehtisham-ul-Haque ${ }^{2}$, Usman Waheed ${ }^{2}$, Muhammad Farooq ${ }^{5}$, Shahzad Ali ${ }^{7}$, Heinrich Neubauer ${ }^{1}$ and Hosny El-Adawy ${ }^{1,8 *}$

${ }^{1}$ Friedrich-Loeffler-Institut, Institute of Bacterial Infections and Zoonoses, Jena, Germany, ${ }^{2}$ Department of Pathobiology, College of Veterinary and Animal Sciences, Jhang, Pakistan, ${ }^{3}$ Climate Change Information Center, Renewable Energy and Expert Systems (CCICREES), Agricultural Research Center, Giza, Egypt, ${ }^{4}$ Department of Brucellosis, Animal Health Research Institute, Agricultural Research Center, Giza, Egypt, ${ }^{5}$ Section of Epidemiology and Public Health, University of Veterinary and Animal Sciences, Lahore Sub-Campus, Jhang, Pakistan, ${ }^{6}$ Department of Pathobiology, KBCMA College of Veterinary and Animal Sciences, Narowal, Pakistan, ${ }^{7}$ Wildlife Epidemiology and Molecular Microbiology Laboratory (One Health Research Group), Discipline of Zoology Department of Wildlife \& Ecology, University of Veterinary and Animal Sciences, Lahore, Pakistan, ${ }^{8}$ Faculty of Veterinary Medicine, Kafrelsheikh University, Kafr El-Sheikh, Egypt
\end{abstract}

Bovine brucellosis is a global zoonosis of public health importance. It is an endemic disease in many developing countries including Pakistan. This study aimed to estimate the seroprevalence and molecular detection of bovine brucellosis and to assess the association of potential risk factors with test results. A total of 176 milk and 402 serum samples were collected from cattle and buffaloes in three districts of upper Punjab, Pakistan. Milk samples were investigated using milk ring test (MRT), while sera were tested by Rose-Bengal plate agglutination test (RBPT) and indirect enzyme-linked immunosorbent assay (i-ELISA). Real-time PCR was used for detection of Brucella DNA in investigated samples. Anti-Brucella antibodies were detected in 37 (21.02\%) bovine milk samples using MRT and in 66 (16.4\%) and 71 (17.7\%) bovine sera using RBPT and i-ELISA, respectively. Real-time PCR detected Brucella DNA in 31 (7.71\%) from a total of 402 bovine sera and identified as Brucella abortus. Seroprevalence and molecular identification of bovine brucellosis varied in some regions in Pakistan. With the use of machine learning, the association of test results with risk factors including age, animal species/type, herd size, history of abortion, pregnancy status, lactation status, and geographical location was analyzed. Machine learning confirmed a real observation that lactation status was found to be the highest significant factor, while abortion, age, and pregnancy came second in terms of significance. To the authors' best knowledge, this is the first time to use machine learning to assess brucellosis in Pakistan; this is a model that can be applied for other developing countries in the future. The development of control strategies for bovine brucellosis through the implementation of uninterrupted surveillance and interactive extension programs in Pakistan is highly recommended.

Keywords: Brucellosis, Brucella abortus, bovines, seroprevalence, risk factors, machine learning 


\section{INTRODUCTION}

Brucellosis is a global widespread zoonotic disease caused by the Gram-negative, facultative intracellular bacterium Brucella $(1,2)$. In animals, the disease is characterized by full-term abortion, infertility, mastitis, and decreased milk production in females and orchitis/epididymitis in males $(3,4)$. However, the infection may stay asymptomatic, and the infected animals may remain undiagnosed (1). Brucellosis is usually transmitted in animals either by contact or through ingestion of contaminated feed and water while in humans by either direct contact with infected animals or ingestion of contaminated animal products $(1,5-8)$.

The Brucella genus includes 12 recognized species with varying host preferences, pathogenicity, and epidemiology $(4,9)$. Primarily, Brucella abortus causes infection in cattle and buffaloes, Brucella melitensis in sheep and goats, and Brucella suis in pigs. However, cross-species infection between different animal species is also possible (10-12). Most infected animals spontaneously shed bacteria in urine, milk, and vaginal secretions. Brucellosis may lead to severe economic losses through abortion, or stillbirth, death of young stock, and extra costs for breeding improvements (12).

Confirmatory diagnosis depends on laboratory-based examination of clinical specimens, e.g., serum or milk. For serological testing usually, a screening test of high sensitivity is followed by a confirmatory test of high specificity (13). Apart from being time and proficiency demanding, the culture of Brucella is hazardous to laboratory personnel and requires a biosafety level-3 facility (14). Thus, the detection of Brucella DNA by PCR in clinical samples is preferred as a tool for definitive diagnosis of brucellosis (15).

Brucellosis is endemic in many countries in Africa, Middle East, Mediterranean Basin, Asia, and Latin America with high records in humans in the Middle East and central Asian regions (16). It is endemic in Pakistan where it affects various livestock species and humans $(12,17)$. Disease burden particularly in bovines is increasing due to commercialization, urbanization, and increasing trends of extensive livestock farming $(18,19)$. Few studies on animal brucellosis are available relating particularly to the region of Northern Punjab. The overall seroprevalence of brucellosis in Pakistan was 3.25-4.4\% in livestock (12). With the use of different serological tests, the seroprevalence in cattle and buffaloes was 4.4-5.06 and 5.2-5.6\%, respectively $(1,12,20)$. However, some studies reported seroprevalences of up to $31.9 \%$ in cattle and up to $47.19 \%$ in buffaloes particularly in those animals kept at organized dairy farms $(21,22)$.

Bearing in mind the economic burden of bovine brucellosis, the present study was designed to determine the seroprevalence, prevailing Brucella spp., and to study the relation between risk factors and the results of diagnostic tests in three districts of Punjab, Pakistan, by using statistical analysis and machine learning.

\section{MATERIALS AND METHODS}

\section{Study Area}

The study was conducted in three selected districts of upper Punjab (Narowal, Gujranwala, and Gujrat), Pakistan (Figure 1).
These three districts have high numbers of animals without previous report on brucellosis. The majority of the rural livelihood relies on small holding dairies averaging 10-15 animals. The Narowal District $\left(32.2730^{\circ} \mathrm{N}, 75.0611^{\circ} \mathrm{E}\right)$ is located northwest to the Sialkot District and bordered at the north by Jammu and Kashmir India and at the southeast by the river Ravi and the Gurdaspur District of India. According to the 9211 Virtual Governance System, the livestock of this district include cattle $(163,900)$, buffaloes $(287,133)$, sheep $(43,156)$, goats $(122,886)$, and equines $(31,956)$.

Gujranwala $\left(32.1566^{\circ} \mathrm{N}, 74.1240 \mathrm{E}\right)$ is located north of the nearby provincial capital of Lahore. The city is Pakistan's fifth most populous metropolitan area. According to the 9211 Virtual Governance System, the livestock of this district include cattle $(196,148)$, buffaloes $(574,962)$, sheep $(93,095)$, goats $(97,636)$, equines (14,992), and camels (78 only).

Gujrat $\left(32.5731^{\circ} \mathrm{N}, 74.1005^{\circ} \mathrm{E}\right)$ is situated at the shore of the river Chenab along the nearby cities of Sialkot and Gujranwala and forms part of the so-called "Golden Triangle" of industrial cities with export-oriented economies. According to the 9211 Virtual Governance System, the livestock of this district includes cattle $(155,346)$, buffaloes $(304,682)$, sheep $(25,388)$, goats $(125,887)$, equines $(40,080)$, and camels ( 62 only).

Important livestock breeds of these districts are Sahiwal and cross-bred cattle, Nili Ravi buffaloes, Teddy and Beetal goats, and Lohi and Kajli sheep. The prevalent diseases of these regions related to livestock are milk fever, mastitis, Degnala disease (aspergillosis), bovine ephemeral fever, contagious caprine pleuropneumonia (CCPP), peste des petits ruminants (PPR), hemorrhagic septicemia (HS), and foot and mouth disease (FMD). Vaccination to these diseases (CCPP, PPR, HS, and FMD) is applied (23). The land of these districts is irrigated by the rivers Ravi and Chenab (https://irrigation.punjab.gov.pk/).

\section{Ethical Approval}

This study was approved by the ethical committee of the College of Veterinary \& Animal Sciences, Jhang University of Veterinary \& Animal Sciences, Lahore, Pakistan via approval number CS/481. Oral and written consent was also taken from each farmer before blood and milk sample collection.

\section{Blood Samples}

In this study, 402 blood samples were collected from cattle (Bos taurus, $n=208$ ) and domestic water buffaloes (Bubalus bubalis, $n=194$ ) located in the districts of Narowal, Gujranwala, and Gujrat in the period March to October 2015. Approximately 4$5 \mathrm{ml}$ of blood were collected aseptically from the jugular vein of each animal in a blood vacutainer containing gel with clotactivating factors (Bio-One ${ }^{\circledR}$, China) that were placed at room temperature for more than $0.5 \mathrm{~h}$ and stored immediately at $4^{\circ} \mathrm{C}$ in an icebox and were transported to the Epidemiology and Public Health Laboratory, College of Veterinary and Animal Sciences, Jhang, Pakistan. All tubes were centrifuged (Eppendorf, Germany) at 5,000 rpm for $5 \mathrm{~min}$ for serum separation. After centrifugation, the supernatants were collected in sterile Eppendorf tubes $(1.5 \mathrm{ml})$ by pipettes and stored at $-20^{\circ} \mathrm{C}$ for further analysis. 

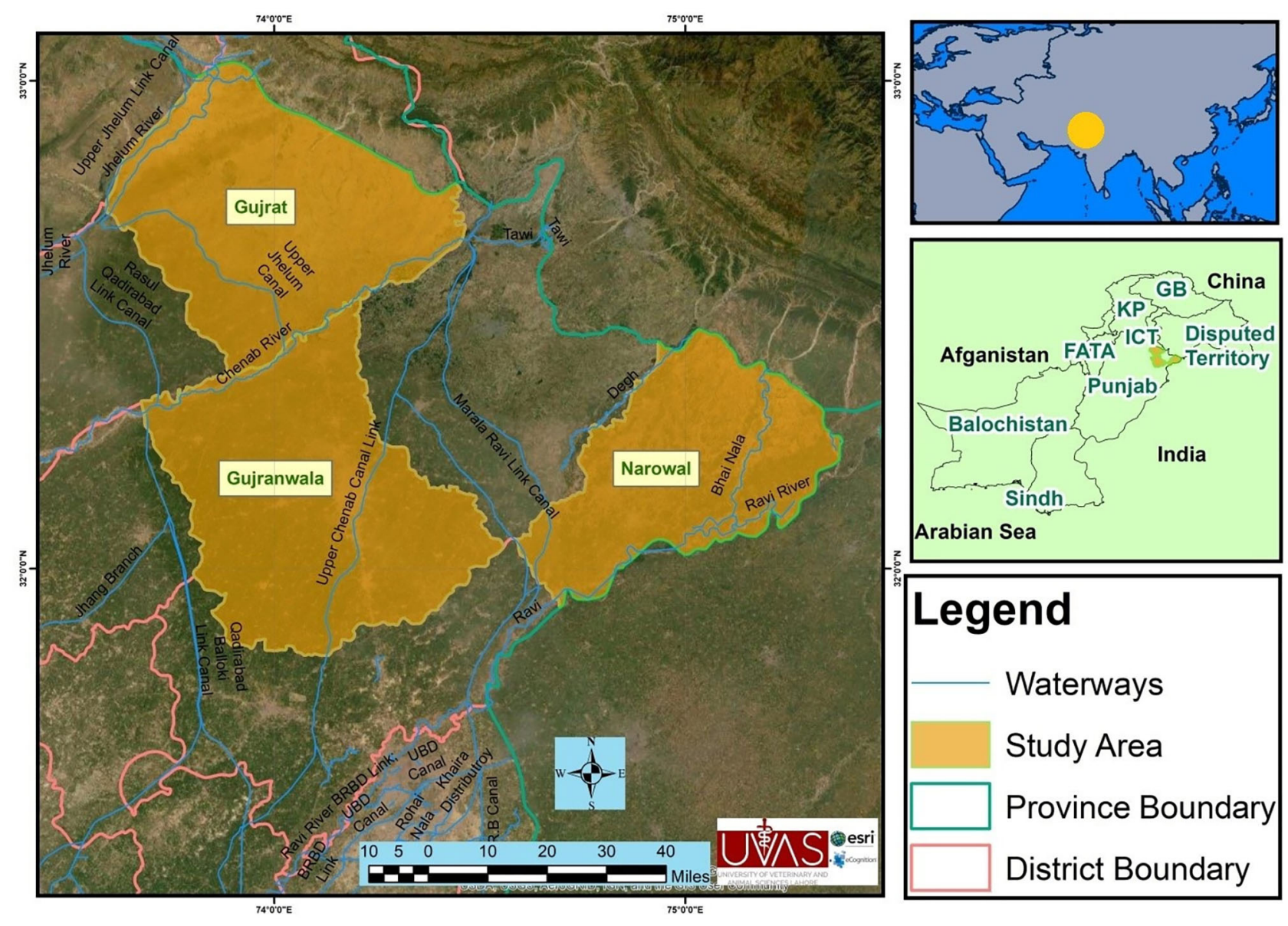

Legend

Waterways

Study Area

Province Boundary

District Boundary

FIGURE 1 | Map of the study area showing districts Gujranwala, Gujrat, and Narowal of upper Punjab, Pakistan.

\section{Milk Samples}

One hundred seventy-six milk samples were collected from the above-mentioned animals including 107 lactating cattle and 69 buffaloes located in the districts of Narowal, Gujranwala, and Gujrat. Samples were collected in the period March to October 2015. These milk samples were collected from animals that were in lactation with apparently healthy non-mastitic milk and from which serum samples were also collected. Five milliliters of milk was collected aseptically with a 10-ml syringe, preserved in an icebox, and transported to the Epidemiology and Public Health Laboratory, College of Veterinary and Animal Sciences, Jhang. Samples were kept at $4^{\circ} \mathrm{C}$ for $24 \mathrm{~h}$ prior to the investigation.

\section{Epidemiological Data Collection}

The demographic (districts) and descriptive epidemiological data related to risk factors (i.e., species, gender, age, pregnancy status, lactation status, herd size, history of abortion, reproductive problems, vaccination history, and health conditions) were collected using a pre-structured questionnaire (Supplementary Material 1).

\section{Analysis of Milk Samples}

Milk samples were investigated by milk ring test (MRT). The MRT antigen was procured from the Veterinary Research Institute Lahore, Pakistan. As per the manufacturer's recommendations, the MRT antigen was kept at room temperature $1 \mathrm{~h}$ before use. The MRT antigen was standardized against the OIE International Standard Serum (OIEISS) to give a positive result at an OIEISS dilution of 1:500 and a negative reaction at 1:1,000. One milliliter of milk sample was added to a test tube, and then $30 \mu \mathrm{l}$ of antigen was added, mixed, and incubated at $37^{\circ} \mathrm{C}$ for $1 \mathrm{~h}$. A sample having a change in color at the top of milk was considered positive (4).

\section{Analysis of Serum Samples}

All sera were screened for anti-Brucella antibodies by RoseBengal agglutination test (RBPT) (RBPT antigen, Veterinary Research Institute, Lahore, Pakistan) and i-ELISA (IDEXX Brucellosis Serum Ab Test kit, IDEXX Laboratories, Inc. Westbrook, United States) according to the manufacturer's recommendations. The RBPT antigen was standardized against the OIEISS to give a positive reaction at a dilution of 1:45 and a negative reaction at a dilution of 1:55. The i-ELISA was 
calibrated according to the OIE specifications to correctly detect the OIE ELISA strong positive standard serum (OIEELISAspSS) (4). The OD value was taken using the ELISA reader $\left(\mathrm{xMark}^{\mathrm{TM}}\right.$ microplate absorbance spectrophotometer, BIO-RAD, USA) at $450-\mathrm{nm}$ wavelength. With the help of OD values, the SP ratio was calculated from the formula:

$$
\mathrm{SP}=\frac{\text { Mean OD sample } \mathrm{x} 100}{\text { Mean OD of positive control }}
$$

Serum samples with SP $<25 \%$ were considered negative. Samples with SP $\geq 25 \%$ were regarded as positive.

\section{Molecular Detection of Brucella spp.}

DNA was extracted from all serum samples using the QIAamp DNA Mini Kit (QIAGEN, Hilden, Germany) according to the instructions of the manufacturer.

Genus Brucella and species-specific (Brucella abortus and Brucella melitensis) real-time PCRs were used for the detection of Brucella DNA (24). PCR was performed using primer and probe (Jena Bioscience GmbH, Germany) sets as given in Table $\mathbf{1}$.

The PCR protocol was modified (volume and temperature) than previously published to obtain the most optimal results where DNA used in this study as template was extracted from serum not from bacterial colonies. Briefly, PCR reaction was performed in $15 \mu \mathrm{l}$ of multiplex PCR mixture with $2 \times$ TaqMan $^{\text {TM }}$ environmental master mix (Applied Biosystems ${ }^{\circledR}$, Darmstadt, Germany), $0.2 \mu \mathrm{M}$ of each primer, $0.1 \mu \mathrm{M}$ of each probe, and 5 $\mu l$ of template DNA. Amplification and real-time fluorescence detection were carried out on a StepOnePlus ${ }^{\mathrm{TM}}$ Real-Time PCR System (Applied Biosystems ${ }^{\circledR}$, Germany). The reaction conditions were as follows: decontamination at $50^{\circ} \mathrm{C}$ for $2 \mathrm{~min}$, initial denaturation at $95^{\circ} \mathrm{C}$ for $10 \mathrm{~min}$ followed by 50 cycles of denaturing at $95^{\circ} \mathrm{C}$ for $25 \mathrm{~s}$, and annealing/elongation at $57^{\circ} \mathrm{C}$

TABLE 1 | Primers and probes sequences used in real-time PCR assays for the detection of Brucella spp., Brucella abortus, and Brucella melitensis in bovine, Pakistan.

\begin{tabular}{|c|c|c|c|}
\hline Target & Primer and probe sequen & nces & Reference \\
\hline Brucella spp. & $\begin{array}{l}\mathbf{5}^{\prime} \text {-GCT CGG TTG CCA ATA TCA } \\
\text { ATG C-3' } \\
\mathbf{5}^{\prime} \text {-GGG TAA AGC GTC GCC AGA } \\
\text { AG-3' } \\
\text { 6-FAM-AAA TCT TCC ACC TTG CCC } \\
\text { TTG CCA TCA-MGB }\end{array}$ & $\begin{array}{l}\text { Forward } \\
\text { Reverse } \\
\text { Probe }\end{array}$ & (24) \\
\hline B. abortus & $\begin{array}{l}\mathbf{5}^{\prime} \text {-GCG GCT TIT CTA CGG TAT } \\
\text { TC-3' } \\
\mathbf{5}^{\prime} \text {-CAT GCG CTA TGA TCT GGT } \\
\text { TAC G-3' } \\
\text { Hex-CGC TCA TGC TCG CCA GAC } \\
\text { TTC AAT G-BHQ1-3 }\end{array}$ & $\begin{array}{l}\text { Forward } \\
\text { Reverse } \\
\text { Probe }\end{array}$ & \\
\hline B. melitensis & $\begin{array}{l}\mathbf{5}^{\prime} \text {-AAC AAG CGG CAC CCC TAA } \\
\text { AA-3' } \\
\mathbf{5}^{\prime} \text {-CAT GCG CTA TGA TCT GGT } \\
\text { TAC G-3' } \\
\text { Cy5-CAG GAG TGT TTC GGC TCA } \\
\text { GAA TAA TCC ACA-BHQ2-3' }\end{array}$ & $\begin{array}{l}\text { Forward } \\
\text { Reverse } \\
\text { Probe }\end{array}$ & \\
\hline
\end{tabular}

(B. abortus and B. melitensis) (24) for $1 \mathrm{~min}$. Sample data scores were confirmed by visual inspection of graphical plots and cycle threshold (CT) values for each sample. CT values below 38 were considered positive. Reference strains of B. abortus S-99 (ATCC 23448), B. melitensis 16M (ATCC 23456) and Brucella suis biovar 1 (ATCC 23444) were used as positive controls. Reference strains of Escherichia coli (ATCC 25922), Staphylococcus aureus (ATCC 25923), and Ochrobactrum intermedium (DSM 17986) were used as negative controls.

\section{Studying the Relationship Between Risk Factors and Diagnostic Test Results Using Statistical Analysis by Pearson's Chi-Squared Test}

Correlation of potential risk factors (geographical location, animal species, age, herd size, and reproductive disease/problem) with molecular detection of Brucella DNA was analyzed using Pearson's chi-squared test $\left(\chi^{2}\right)$. The estimation of $\chi^{2}$ was done using RStudio Version 1.1.463.

\section{Studying the Relationship Between Risk Factors and Diagnostic Test Results Using Machine Learning}

Machine learning has been used widely in prediction, clustering, and classification based on features. One of the powerful machine learning techniques is decision tree (25), which is used for modeling and classifying data. Decision tree was particularly

TABLE 2 | Conversion of risk factor categories into numeric values for machine learning model.

\begin{tabular}{|c|c|c|}
\hline Risk factor (attribute) & Category & Value \\
\hline \multirow[t]{3}{*}{ Location } & Gujranwala & 1 \\
\hline & Gujrat & 2 \\
\hline & Narowal & 3 \\
\hline \multirow[t]{2}{*}{ Genus/species } & Cattle (Bos taurus) & 1 \\
\hline & Buffalo (Bos bubalus) & 2 \\
\hline \multirow[t]{2}{*}{ Sex } & Male & 1 \\
\hline & Female & 2 \\
\hline \multirow[t]{3}{*}{ Age } & $7-10$ years & 1 \\
\hline & $3-7$ years & 2 \\
\hline & $2-3$ years & 3 \\
\hline \multirow[t]{3}{*}{ Herd size } & $1-10$ & 1 \\
\hline & $11-30$ & 2 \\
\hline & $>30$ & 3 \\
\hline \multirow[t]{2}{*}{ Reproductive disease/problem } & Yes & 1 \\
\hline & No & 2 \\
\hline \multirow[t]{2}{*}{ History of abortion } & Yes & 1 \\
\hline & No & 2 \\
\hline \multirow[t]{2}{*}{ Pregnancy } & Yes & 1 \\
\hline & No & 2 \\
\hline \multirow[t]{2}{*}{ Lactation } & Yes & 1 \\
\hline & No & 2 \\
\hline
\end{tabular}


chosen as a suitable machine learning technique for classifying the current categorical small-sized data. It also builds a model for the features (risk factors) based on their significance. The feature set represents the dependent variables, while serum test results were used as the independent or target variable. Exploring the significance of the features recorded for animals under sampling is the objective of using machine learning in this work. Nine categorical features representing the dependent variables were recorded for the 402 animals in the current work. These features were location, genus, species, sex, age, herd size, reproductive disease/problem, history of abortion, pregnancy, and lactation.

Decision tree technique is not only a classifier but also a model that can be visually seen and easily understood, which is important to the inferences beyond the model. It also explains the rules used for dividing data using inferred rules for this division. The aim was to predict a value of certain variables based on a created model. It uses training samples consisting of features (attributes). The data were divided into subsets, where data in lower subsets were purer than data in upper subsets. The attribute chosen to be represented in a node was the attribute with the highest information gain (Gini) of all attributes. The resulted model was represented in a tree-like shape, where internal node was a test conducted on an attribute, branches were the results of the test, and leaf nodes represented the decision taken. A pipeline was proposed by Fountain-Jones et al. (26) for using machine learning on exposure data (26). This pipeline consists of steps to be applied on exposure data in order to discover significant patterns in it. The following steps demonstrate to conduct machine learning on recorded data.

\section{Data Pre-processing}

All features are categorical so they need to be encoded or converted to numeric values. This conversion is shown in Table 2.

\section{Model Training}

The data were divided into a training set of 281 cases (70\%) and a test set of 121 cases (30\%). Three different runs have been conducted on the features, and the results of three serum tests RBPT, i-ELISA, and real-time PCR were used as the independent variable. Three different trees resulted from the experiment and are shown in Figures 2-4, where the maximum depth of the trees was set to 4 in order to fit the presentation.

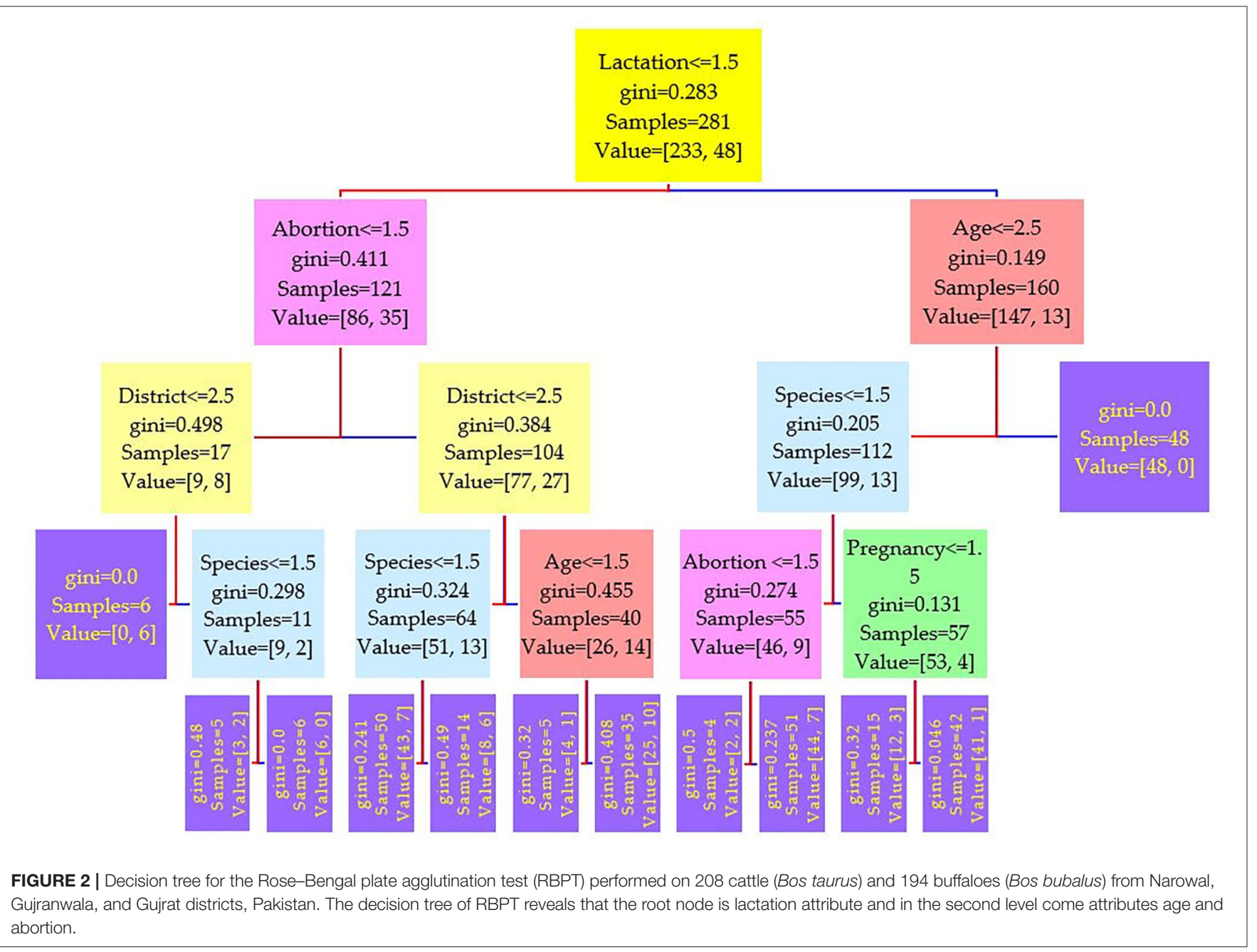




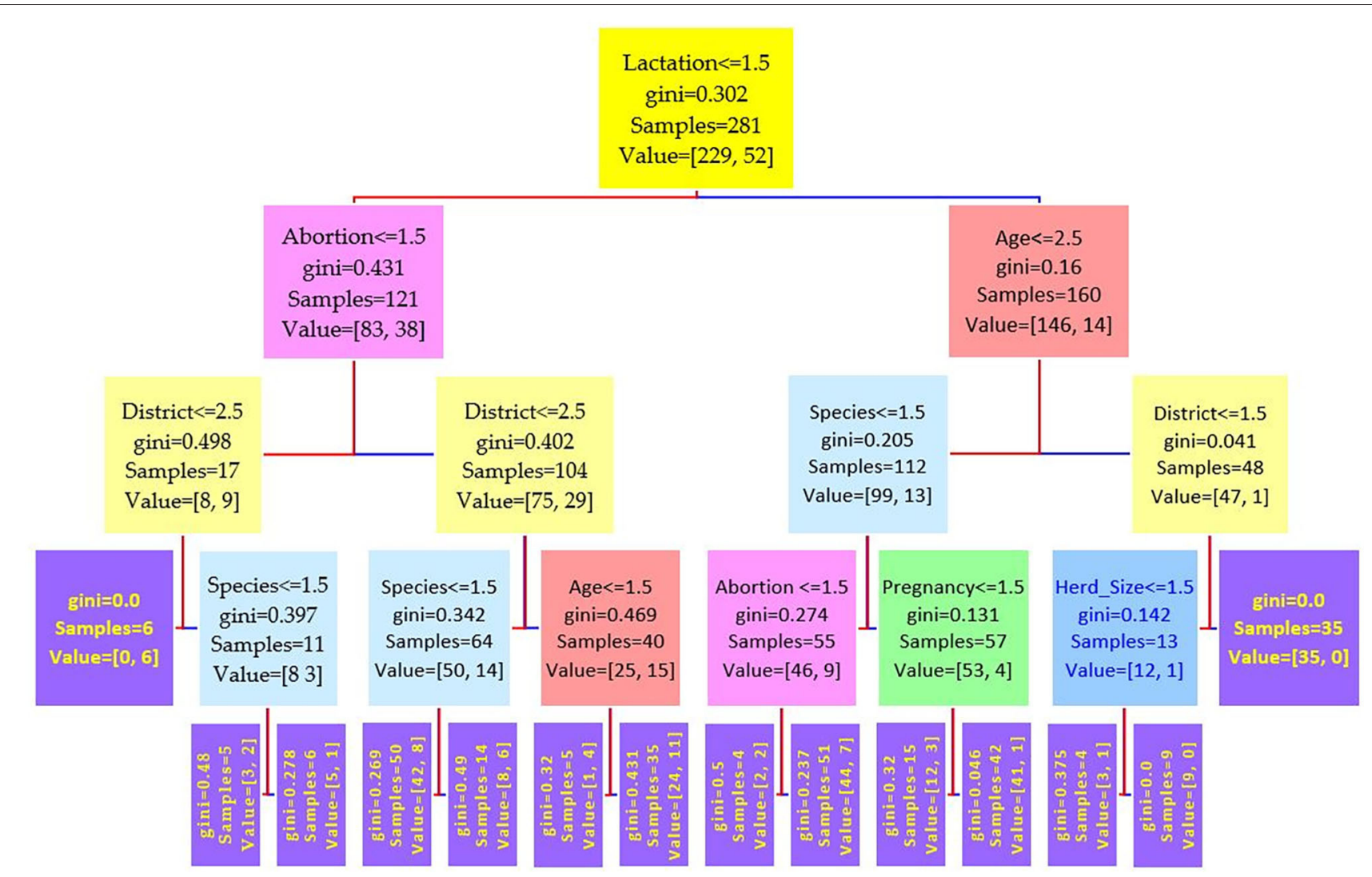

FIGURE 3 | Decision tree for the i-ELISA performed on 208 cattle (Bos taurus) and 194 buffaloes (Bos bubalus) from Narowal, Gujranwala, and Gujrat districts, Pakistan. The decision tree of i-ELISA reveals that the root node is lactation attribute and in the second level come attributes age and abortion.

\section{Model Performance Evaluation}

Performance of the machine learning model was evaluated to find out if it actually worked and if it gave trustworthy predictions on new data other than the data it was trained on. The performance metrics precision or positive predicted value (PPV), recall or negative predicted value (NPV), accuracy, and area under the receiver operating characteristic curve (AUC ROC) were calculated from prediction scores for the serum tests RBPT, i-ELISA, and real-time PCR.

\section{RESULTS}

\section{Prevalence of Anti-Brucella Antibodies in Bovine Milk and Serum}

Out of 176 milk samples collected from lactating bovines, 37 (21.02\%) were positive. Anti-Brucella antibodies were detected in $19(17.7 \%)$ and $18(26.08 \%)$ of 107 from cattle and 69 from buffaloes milk samples, respectively (Table 3). Moreover, 16.4\% ( 66 out of 402 ) and $17.7 \%$ (71 out of 402 ) bovine sera were found positive for anti-Brucella antibodies using RBPT and i-ELISA, respectively (Table 3). A higher seropositivity was found in cattle (18.75 and $19.71 \%$ ) than in buffaloes (13.91 and 15.46\%) using RBPT and i-ELISA, respectively (Table 3 ).

Twenty eight animals were positive to all the three tests (Figure 5A). The real-time PCR was positive when both tests or either the RBPT or i-ELISA was positive. The RBPT and iELISA exclusively detected one and three animals, respectively. The i-ELISA detected the highest number of positive animals (71) followed by RBPT (66) and real-time PCR (31).

A total of 176 lactating animals were additionally tested by MRT. The test detected one animal exclusively and another animal that was only positive on the real-time PCR (Figure 5B). On the other hand, the MRT failed to detect 15 animals that were positive to one or more of the other tests.

\section{Detection of Brucella spp. DNA in Bovine Sera}

Brucella DNA was detected in serum samples positive by RBPT or i-ELISA. Brucella abortus DNA was identified in 31 (7.7\%) bovine sera (Table 3). Brucella DNA was not amplified from seronegative serum samples. A higher number of Brucella DNA positive samples were detected in $18(9.27 \%)$ buffaloes than in $13(6.25 \%)$ cattle. Brucella DNA was amplified from 8.21, 7.46, and $7.46 \%$ of bovine sera from Narowal, Gujranwala, and Gujrat districts, respectively.

\section{Statistical Results of Chi-Squared Test}

The risk factors geographical location, animal species, age, herd size, and reproductive disease/problem revealed no statistical 


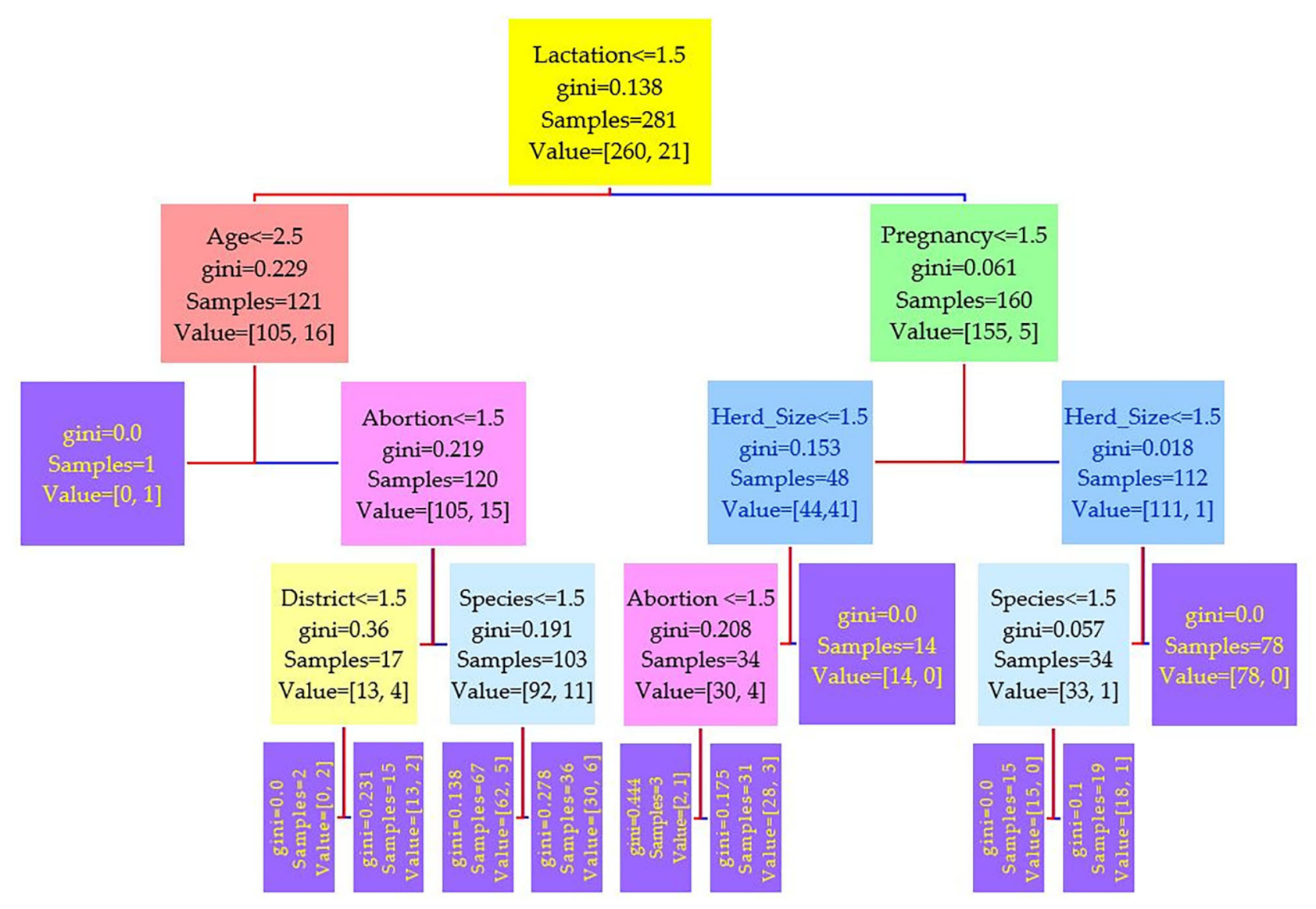

FIGURE 4 | Decision tree for the real-time PCR performed on 208 cattle (Bos taurus) and 194 buffaloes (Bos bubalus) from Narowal, Gujranwala, and Gujrat districts, Pakistan. The decision tree of real-time PCR reveals that the root node is lactation attribute and in the second level come attributes age and pregnancy.

significance by Pearson's chi-squared test with diagnostic test results (RBPT, i-ELISA, and real-time PCR) as shown in Table 4.

\section{Performance Results of Machine Learning Model}

The evaluation parameters of machine learning model revealed that the three tests recorded performance metrics very close to each other (Table 5). The PPVs were $\leq 50 \%$, where the lowest was for real-time PCR (43\%) while the highest was that of i-ELISA (50\%) and RBPT was $44 \%$. NPVs were also low and close to each other, where the highest value was $42 \%$ for i-ELISA while the lowest was 30\% for real-time PCR, and RBPT had a value of 39\%. Likewise, accuracy was high for all tests (more than 83\%) with similar values. ROC AUC values were moderate (63-67\%) and close to each other as well.

\section{Relationship Between Risk Factors and Diagnostic Test Results Using Machine Learning}

Comparing the results of the three models of diagnostic tests (Figures 2-4) revealed that the lactation attribute was the root node in all tests, indicating that this attribute was significant.
The second level after the root node in RBPT and i-ELISA was identical involving both age and abortion risk factors. In real-time PCR test model, abortion was replaced by pregnancy.

\section{DISCUSSION}

Brucellosis is one of the most contagious zoonoses that are still endemic in many countries including Pakistan $(1,16)$. It is not only an occupational risk to livestock professionals but also a food-borne threat to consumers of animal products (27). Abortions, infertility, and reduction in milk production are adverse effects of brucellosis on livestock production. In developing countries, livestock is the basis of livelihood for about 95\% of the rural population (12) providing food, skin, fibers, manure (fertilizer or fuel), and draft power. The identification of Brucella spp. in various farm animals and wildlife species highlights their role in disease spread (28-33).

Serological tests are unable to differentiate Brucella spp., as antibodies to smooth brucellae lipopolysaccharide (LPS) highly cross-react. Isolation and identification of the etiological agent from biological specimens remain the "gold standard" for epidemiological investigation and determination of 
TABLE 3 | Seroprevalence and molecular detection of Brucella DNA in bovine milk and sera collected from Narowal, Gujranwala, and Gujrat districts of upper Punjab, Pakistan.

\begin{tabular}{|c|c|c|c|c|c|c|c|c|c|}
\hline \multirow[t]{2}{*}{ District } & \multirow[t]{2}{*}{ Animal } & \multirow{2}{*}{$\begin{array}{c}\text { Number of } \\
\text { milk samples }\end{array}$} & \multirow{2}{*}{$\begin{array}{c}\text { Number of } \\
\text { serum samples }\end{array}$} & \multicolumn{3}{|c|}{ Serological examination } & \multicolumn{3}{|c|}{ Molecular identification } \\
\hline & & & & $\begin{array}{c}\text { MRT * No. } \\
(\%)\end{array}$ & $\begin{array}{c}\text { RBPT * No. } \\
(\%)\end{array}$ & $\begin{array}{c}\text { i-ELISA * No. } \\
(\%)\end{array}$ & $\begin{array}{c}\text { Real-time PCR } \\
\text { No. (\%) }\end{array}$ & $\begin{array}{l}\text { Brucella } \\
\text { spp. }\end{array}$ & $\begin{array}{c}\text { Cq/Ct } \\
\text { values* }\end{array}$ \\
\hline \multirow[t]{2}{*}{ Narowal } & ++ Cattle & 39 & 65 & $9(23.1)$ & $16(24.6)$ & $16(24.6)$ & $4(6.15)$ & Brucella abortus & $32,35,36,32$ \\
\hline & +++Buffalo & 42 & 69 & $8(19.04)$ & $9(13.04)$ & $12(17.4)$ & $7(10.1)$ & B. abortus & $36,32,30,32,31,29,30$ \\
\hline Subtotal & & 81 & 134 & $17(20.9)$ & 25 (18.6) & $28(20.9)$ & $11(8.21)$ & & \\
\hline \multirow[t]{2}{*}{ Gujranwala } & Cattle & 30 & 70 & 5 (16.6) & $11(15.7)$ & $13(18.5)$ & $4(5.71)$ & B. abortus & $35,32,32,35$ \\
\hline & Buffalo & 9 & 64 & $4(44.4)$ & $8(12.5)$ & $8(12.5)$ & $6(6.37)$ & B. abortus & $30,31,31,35,29,33$ \\
\hline Subtotal & & 39 & 134 & $9(23.07)$ & $19(14.17)$ & $21(15.6)$ & $10(7.46)$ & & \\
\hline \multirow[t]{2}{*}{ Gujrat } & Cattle & 38 & 73 & $5(13.1)$ & $12(16.4)$ & $12(16.4)$ & $5(6.84)$ & B. abortus & $32,34,37,34,30$ \\
\hline & Buffalo & 18 & 61 & $6(33.3)$ & $10(16.3)$ & $10(16.3)$ & $5(8.19)$ & B. abortus & $27,36,32,32,35$ \\
\hline Subtotal & & 56 & 134 & $11(19.6)$ & 22 (16.4) & $22(16.4)$ & $10(7.46)$ & & \\
\hline Grand-total & & 176 & 402 & 37 (21.02) & $66(16.4)$ & $71(17.7)$ & $31(7.7)$ & & \\
\hline
\end{tabular}

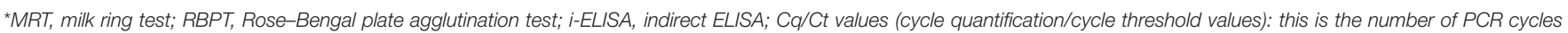

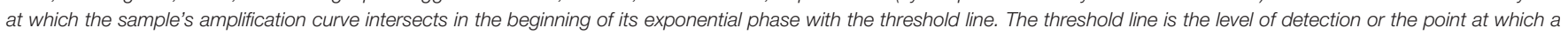

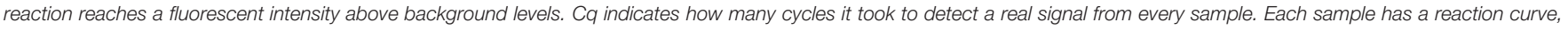
which is a plot of the number of cycles vs. fluorescence intensity.

++ Bos taurus.

${ }^{+++}$Bos bubalus.

Italic values indicates Subtotal (\%).
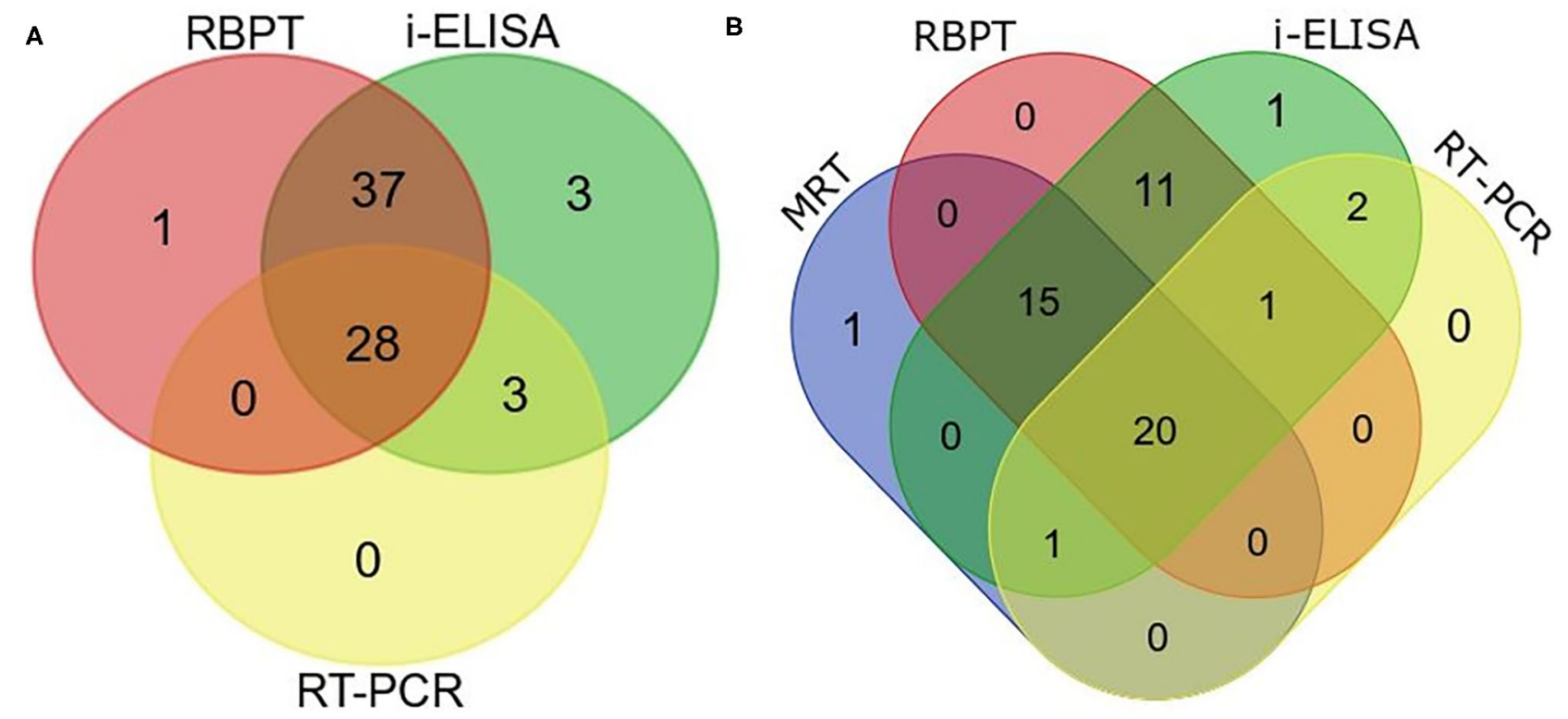

FIGURE 5 | Venn diagram of correlations of serological tests and real-time PCR expressed as numbers of positive cattle (Bos taurus) and buffaloes (Bos bubalus) from the three target districts. (A) Results of all the 402 sera tested by Rose-Bengal plate agglutination test (RBPT), i-ELISA, and real-time PCR. (B) Results for the 176 lactating animals where milk ring test (MRT) was additionally performed.

antimicrobial resistance, but these methods are time-consuming and hazardous. The detection of Brucella DNA by PCR in clinical samples is a preferred tool for conclusive diagnosis of brucellosis (15). Despite the low sensitivity of the real-time PCR resulting from the presence of only trace amounts of DNA in serum, the test achieved the highest accuracy (91\%) than the RBPT and i-ELISA (Table 3) known for their sensitivity. Brucella abortus DNA was detected in sera from 13 cattle and 18 buffalo cows. This current finding agrees with previous reports indicating the endemicity of $B$. abortus in bovines in Pakistan $(17,21,32,34-36)$. One study also reported Brucella melitensis infection in bovines (12). Molecular studies on brucellosis are 
TABLE 4 | Statistical relationship of risk factors with detection of bovine brucellosis in Narowal, Gujranwala, and Gujrat districts of upper Punjab, Pakistan.

\begin{tabular}{cc}
\hline Variable & $\begin{array}{c}\text { Serological examination } n(\%) \\
n(\%)\end{array}$ \\
& Real-time-PCR, \\
RBPT & i-ELISA
\end{tabular}

\section{Geographical location}

Gujranwala $(n=134)$

Gujrat $(n=134)$

Narowal $(n=134)$

$p$-value*

$\chi^{2}$

Df

95\% Cl

OR

Species

Cattle $(n=208)$

Buffaloes $(n=194)$

$p$-value*

$\chi^{2}$

Df

95\% Cl

OR

\section{Age}

$7-10$ years $(n=98)$

3-7 years $(n=236)$

$2-3$ years $(n=68)$

$p$-value*

$\chi^{2}$

Df

95\% Cl

OR

\section{Herd size}

$1-10(n=128)$

$11-30(n=138)$

$>30(n=136)$

$p$-value*

$\chi^{2}$

Df

95\% Cl

OR

Reproductive disease/problem

Yes $(n=374)$

No (28)

$p$-value*

$\chi^{2}$

Df

$95 \% \mathrm{Cl}$

OR

History of abortion

Yes $(n=39)$

No $(n=363)$

$p$-value*

$\chi^{2}$

Df

95\% Cl

OR

66 (17.64)

0

$-$

-

0-Inf

0

14 (35.89)

52 (14.32)

0.3984

0.71309

0.2257425

2.0039428

0.6610627
$10(7.46)$

$10(7.46)$

11 (8.21)

28 (20.89)

0.9276

0.15033

2

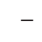

41 (19.71)

30 (15.46)

0.1412

2.1652

1

0.7410196

4.8877704

1.880346

$27(27.55)$

$41(17.37)$

3 (4.41)

0.7936

0.4623

2

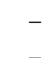

$$
\begin{gathered}
22(17.18) \\
22(15.94) \\
27(19.85) \\
0.9798 \\
0.040852
\end{gathered}
$$

2

70 (18.71)

1 (3.57)

0.5067

0.44094

1

0.00000

89.19948

0

$16(41.02)$

55 (15.15)

0.4829

0.49229

1

$0.2505977-$

\begin{tabular}{|c|c|c|c|}
\hline \multirow[t]{2}{*}{ Variable } & \multicolumn{2}{|c|}{ Serological examination $n(\%)$} & \multirow{2}{*}{$\begin{array}{c}\text { Real-time-PC } \\
n(\%)\end{array}$} \\
\hline & RBPT & i-ELISA & \\
\hline \multicolumn{4}{|l|}{ Pregnancy } \\
\hline Yes $(n=177)$ & $37(20.90)$ & $39(22.03)$ & $16(9.04)$ \\
\hline No $(n=225)$ & $29(12.88)$ & $32(14.22)$ & $15(6.66)$ \\
\hline$p$-value* & 0.6816 & 0.7573 & \\
\hline$\chi^{2}$ & 0.16835 & 0.095536 & \\
\hline Df & \multicolumn{2}{|c|}{1} & \\
\hline $95 \% \mathrm{Cl}$ & $\begin{array}{c}0.464294- \\
3.067330\end{array}$ & $\begin{array}{c}0.4489188- \\
2.8947825\end{array}$ & \\
\hline OR & 1.1939 & 1.14108 & \\
\hline \multicolumn{4}{|l|}{ Lactation } \\
\hline Yes $(n=176)$ & $47(26.70)$ & $51(28.97)$ & $24(13.63)$ \\
\hline No $(n=226)$ & $19(8.41)$ & $20(8.85)$ & $7(3.097)$ \\
\hline$p$-value* & 0.5198 & 0.5563 & \\
\hline$\chi^{2}$ & 0.41423 & 0.34623 & \\
\hline Df & \multicolumn{2}{|c|}{1} & \\
\hline $95 \% \mathrm{Cl}$ & $\begin{array}{c}0.2247314- \\
2.1213957\end{array}$ & $\begin{array}{c}0.2336189- \\
2.1616710\end{array}$ & \\
\hline OR & 0.723859 & 0.745854 & \\
\hline
\end{tabular}

2.1199847

0.7135534 2 (2.94)
TABLE 4 | Continued

$10(10.2) \quad$ *Statistical value of significance: $p \leq 0.05$

19 (8.05) $\quad \chi^{2}$, Pearson's chi-squared test; Df, degree of freedom; Cl, confidence interval; OR, odds ratio.

TABLE 5 | Performance evaluation metrics of machine learning ${ }^{\star}$ model calculated from prediction scores for the serum tests RBPT, i-ELISA, and real-time PCR.

\begin{tabular}{lccc}
\hline & RBPT & i-ELISA & Real-time PCR \\
\hline Precision (PPV) $^{\star *}$ & $44 \%$ & $50 \%$ & $43 \%$ \\
Recall (NPV) $^{\star \star \star}$ & $39 \%$ & $42 \%$ & $30 \%$ \\
Accuracy $^{\star \star \star \star}$ & $83 \%$ & $84 \%$ & $91 \%$ \\
ROC AUC & $65 \%$ & $67 \%$ & $63 \%$ \\
\hline
\end{tabular}

RBPT, Rose-Bengal agglutination test; PPV, positive predicted value; NPV, negative predicted value; AUC ROC, area under the receiver operating characteristic curve.

*Machine learning steps involved supervised learning by decision tree algorithm, classification of animals as positive or negative based on the model of each diagnostic test, and evaluation of the established models by matching the predicted (classified) values as an output from each model and the real results of the diagnostic test.

${ }^{\star *}$ Precision (random error) is the agreement among repeated analyses of a sample. It is also called positive predicted value. It means the odds that the test method has made a correct prediction when it predicts a positive value.

${ }^{\star * \star}$ Recall (sensitivity or negative predicted value) is how often the test method is making a correct prediction when the actual value is positive.

${ }^{* * * *}$ Accuracy is nearness of a test value to the actual value. It is the number of correct predictions made as a ratio of all predictions made.

${ }^{* * * * *} R O C$ AUC is the area under the receiver operating curve indicating the ability of a binary classifier to discriminate between positive and negative classes at various diagnostic thresholds. An ROC curve is a graph showing the performance of a test method at all classification thresholds by plotting the true positive rate (on $y$-axis) vs. the false positive rate (on $x$-axis).

only limited to certain regions, and scarce literature is available relevant to Pakistan.

Serology remains the practical tool for the diagnosis of brucellosis in bovines. A vast number of serological tests used for 
screening have been developed starting with a simple qualitative agglutination test and progressing to sophisticated primary binding assays. RBPT is a widely accepted method for screening of anti-Brucella antibodies in bovines (1). However, a crossreaction with antibodies of non-Brucella antigens negatively influences specificity (34). False-negative reactions can occur in the RBPT due to prozoning with sera containing very high levels of antibody. In the current study, the RBPT agreed with i-ELSA in the majority of animals (65 positives) with a single cow exclusively positive to the RBPT only, three animals positive to the i-ELISA only, and three animals commonly positive to the i-ELISA and the real-time PCR altogether (Figure 5A). The RBPT false-negative rate, accuracy, and the ROC AUC $(39,83$, and $65 \%$ ) were close to the corresponding values of the i-ELISA $(42,84$, and $67 \%)$ in that order (Table 3). The RBPT is a suitable rapid screening test for brucellosis, followed by confirmatory testing (13).

The indirect enzyme immunoassays generally have very high sensitivity, but they cannot distinguish B. abortus S19 postvaccinal antibodies. Indirect ELISA proved to be highly sensitive and is the recommended test for brucellosis diagnosis in wellequipped diagnostic facilities $(4,37)$. Being a quantifier of antibody concentration unrelatedly to its biological activity with a reliable low detection limit (38), the i-ELISA in this study detected the highest number of positives $(71,17.7 \%)$ as in Table 3. All in all, the i-ELISA achieved the best diagnostic performance parameters in comparison to the RBPT and real-time PCR (Table 3).

Screening of milk samples using MRT is recommended by the OIE for herd prevalence/freedom of infection (4). However, the diagnostic sensitivity and specificity of MRT are low if compared with milk ELISA (39). The MRT is prone to false reactions caused by abnormal milk such as mastitic milk, colostrums, and milk of the late lactation cycle. Still, in spite of its problems, it is an inexpensive screening test if combined with other tests. Of the 176 lactating bovines tested, the MRT detected 37 (21.02\%) positives including a cow exclusively discovered by the MRT (Figure 5B, Table 3).

The prevalences in milk (21.02\%) and serum samples $(17.7 \%$ by i-ELISA) found in this study are slightly higher than in previous reports on bovine brucellosis (0-15\%) in Pakistan $(20,21,40)$. Contrary to our findings of 16.4 and $17.7 \%$ seroprevalences by RBPT and i-ELISA, respectively, few studies reported corresponding seroprevalences of 5.6 and $4.7 \%$ by RBPT and i-ELISA, respectively, which were significantly $(p<0.05)$ higher in buffaloes than in cattle $(1,12)$. Cattle $(18.75$ and $19.71 \%$ ) were more often found positive than buffaloes (13.91 and $15.46 \%$ ) in this study by RBPT and i-ELISA, respectively. These results are in agreement with previous findings $(12,41,42)$. Hence, reports with a higher prevalence in buffaloes than in cattle exist $(1,43)$. The phenomenon toward biological affinity in cattle and buffaloes for brucellosis remains unclear.

Farmers in studied districts (Narowal, Gujranwala, and Gujrat) are used to rear animals in small and medium herds. These areas are irrigated by canals and the rivers of Ravi and Chenab to support the economical production of livestock. This study found a lower disease frequency in regions with a dry environment than in those regions that have access to rivers/irrigation water. This points to the fact that Brucella is an environmental contaminant, as illegal disposal of infected materials contributes to the spread of disease as known for the River Nile and its canals in Egypt (44). Instead of culling, infected animals are sold in the markets resulting in further spread of infection. It can be assumed that the incidence of brucellosis in bovines is increasing day by day in Pakistan, which is comparable with the situation in sheep and goats (35).

Statistical association of risk factors with brucellosis test results (RBPT, i-ELISA, and real-time PCR) was studied using chi-squared test. There was no significant relationship recorded (Table 4). The authors, therefore, resorted to an alternative means of investigation, where infectious diseases in general and brucellosis in particular are tricky in the sense that they are unpredictable with so many factors that affect the course of infection and transmission. Machine learning as a branch of artificial intelligence is a very promising tool for monitoring and better understanding of health and disease. One of the uses of machine learning by mathematicians is to assess variables related to infection using a diversity of input data (e.g., location, genus, species, sex and age of animals, herd size, reproductive disease/problem, history of abortion, pregnancy, and lactation).

After building the machine learning model based on decision tree, it was then necessary to assess its performance before its application on the data (Table 5). Each of the performance metrics values of precision, recall, accuracy, and ROC AUC calculated from prediction scores for RBPT, i-ELISA, and realtime PCR were close to each other, indicating that these tests give close results. As to the performance of machine learning model, it achieved an acceptable accuracy over $83 \%$, which is fair enough. Although the PPVs and NPVs were low affecting the model performance as a positive negative classifier, the main objective of building the model was not only to be used as a classifier but also for comparing/arranging the significance of risk factors and their association with seroprevalence.

A higher proportion of anti-Brucella antibodies were detected in lactating and pregnant animals. These findings are in agreement with reports from India, Zimbabwe, and Sudan, where the risk of brucellosis increased in pluriparous cows (4547). Significant high prevalence was also observed in lactating $(22.35 \%)$ vs. non-lactating $(2.46 \%)$ cattle from Ethiopia (48). These findings may be caused by the fact that brucellae grow in the gravid uterus of cattle in large numbers due to erythritol affinity to make the gravid uterus a predilection site (49). The ability to catabolize erythritol preferentially over other sugars by bacteria of the genus Brucella is associated with the capability to induce abortions in infected ruminants (50). The phenomenon of high prevalence in lactating animals is not well-understood but may be linked to the production stress, which induces clinical infection from latent bacteria residing in the supramammary lymph nodes.

A number of studies in Pakistan documented age, species/breed, the status of animal production/reproduction, history of abortion, and underlying reproductive issues as potential risk factors for brucellosis at the individual or herd level $(1,12,43,51-53)$. These findings are in accordance with 
the results of the current study. Prevalence was closely associated with age and history of abortion. Animals older than 7 years had higher seroprevalences. These results are in agreement with similar findings from previous reports $(45,54)$. Younger age may be connected to sexual immaturity and/or passive immunity acquired by maternal antibodies (45).

High seroprevalences were recorded in herds with more than 30 animals in this study. Brucellosis is frequently reported from intensive dairy farms (1). Herd size and geographical location were not found to be associated with brucellosis prevalence in this study, which is in agreement with previous studies in Pakistan $(43,55)$ but former reports in other parts of the country $(1,12,53)$.

A higher seropositivity of brucellosis was observed in animals associated with a history of abortion and underlying reproductive problems (38.5 and 18.7\%), respectively. These are the cardinal symptoms of Brucella infection, and thus these findings are not surprising. Significant association of brucellosis with the occurrence of abortions in cattle and reproductive problems, i.e., retained fetal membranes, was reported from various regions in Ethiopia $(48,56,57)$. Similar results were also reported by other authors $(45,51,52)$.

The determination of brucellosis prevalence and associated risk factors is an important determinant to predict the epidemiological status of the disease. Eradication of brucellosis is only possible when positive animals are culled. Consequently, the trade or movement of Brucella-positive animals must be prohibited, and a compensation policy must be brought into force to get acceptance of farmers for these measurements. Additionally, biosafety and biosecurity practices must be set in force to decrease the incidence of brucellosis (58).

Not only surveillance and vaccination still remain uncoordinated, but they also constitute a financial limitation in developing countries. Therefore, brucellosis control should take good advantage of the rapid progress in the field of artificial intelligence including machine learning for computational analysis of big epidemiological data aiming for more effective disease management. Machine learning, as one of the necessary components for digitalization of animal health, is expected to open up many possibilities that boost precision livestock industry, health, and well-being, offering new opportunities for future farms.

\section{CONCLUSION}

Brucellosis remains a lingering infection jeopardizing dairy herds in Pakistan. Brucella abortus was identified as a causative agent of bovine brucellosis in upper Punjab, Pakistan. Animals without any sign of illness may remain carriers shedding brucellae into

\section{REFERENCES}

1. Jamil T, Melzer F, Saqib M, Shahzad A, Khan Kasi K, Hammad Hussain M, et al. Serological and molecular detection of bovine brucellosis at institutional livestock farms in Punjab, Pakistan. Int J Environ Res Public Health. (2020) 17:1412. doi: 10.3390/ijerph17041412 the environment. Machine learning results revealed that the lactation status was the root node in all tests supporting the real findings, while age, abortion, and pregnancy were located in a lower level of significance. To the authors' best knowledge, this is the first time to use machine learning to assess brucellosis risk factors in Pakistan, a model that can be applied for other developing countries in the future. Elimination of positive shedders, development of control strategies, and interactive extension programs for brucellosis are urgently needed in developing countries like Pakistan.

\section{DATA AVAILABILITY STATEMENT}

The raw data supporting the conclusions of this article will be made available by the authors, without undue reservation.

\section{ETHICS STATEMENT}

This study was approved by the ethical committee of the College of Veterinary \& Animal Sciences, Jhang- University of Veterinary \& Animal Sciences, Lahore, Pakistan via approval number CS/481. Oral and written consent was also taken from each farmer before blood and milk sample collection.

\section{AUTHOR CONTRIBUTIONS}

Data curation was carried out by AK. Formal analysis was performed by $\mathrm{AK}, \mathrm{AS}$, and $\mathrm{AH}$. Investigation was done by $\mathrm{AK}$, IK, SE-u-H, UW, MF, SA, and HE-A. Methodology was provided by AK, FM, HN, and HE-A. Supervision was carried out by FM, IK, ME, HN, and HE-A. Writing - original draft was done by $\mathrm{AK}$ and HE-A. Writing - review and editing were performed by AK, FM, AH, AS, IK, ME, SE-u-H, UW, MF, SA, HN, and HE-A. All authors contributed to the article and approved the submitted version.

\section{FUNDING}

This research work was supported by the International Research Project German Biosecurity Program of the Federal Foreign Office, Germany, in collaboration with Friedrich-LoefflerInstitut, Jena, Germany.

\section{SUPPLEMENTARY MATERIAL}

The Supplementary Material for this article can be found online at: https://www.frontiersin.org/articles/10.3389/fvets. 2020.594498/full\#supplementary-material

2. Peng C, Zhou H, Guan $\mathrm{P}$, Wu W, Huang DS. An estimate of the incidence and quantitative risk assessment of human brucellosis in mainland China. Transbound Emerg Dis. (2020). doi: 10.1111/tbed. 13518

3. Kaaboub EA, Ouchene N, Ouchene-Khelifi NA, Khelef D. Serological and histopathological investigation of brucellosis in 
cattle in Medea region, Northern Algeria. Vet World. (2019) 12:713-8. doi: 10.14202/vetworld.2019.713-718

4. OIE. Brucellosis (Brucella abortus, B. melitensis and B. suis) (infection with $B$. abortus, B. melitensis and B. suis) Manual of Diagnostic Tests and Vaccines for Terrestrial Animals 2019. Paris: OIE. World Health Organization for Animal Health World Organisation for Animal Health (Office International des Épizooties) (2019). p. 355-98.

5. Hassan H, Salami A, Nehme N, Hakeem RA, Hage JE, Awada R. Prevalence and prevention of brucellosis in cattle in Lebanon. Vet World. (2020) 13:36471. doi: $10.14202 /$ vetworld.2020.364-371

6. Liu Z, Shen T, Wei D, Yu Y, Huang D, Guan P. Analysis of the epidemiological, clinical characteristics, treatment and prognosis of human brucellosis during 2014-2018 in Huludao, China. Infect Drug Resist. (2020) 13:435-45. doi: 10.2147/IDR.S236326

7. Njenga MK, Ogolla E, Thumbi SM, Ngere I, Omulo S, Muturi M, et al. Comparison of knowledge, attitude, and practices of animal and human brucellosis between nomadic pastoralists and non-pastoralists in Kenya. BMC Public Health . (2020) 20:269. doi: 10.1186/s12889-020-8362-0

8. Khan AU, Melzer F, El-Soally S, Elschner MC, Mohamed SA, Sayed Ahmed MA, et al. Serological and molecular identification of Brucella spp. in pigs from Cairo and Giza governorates, Egypt. Pathogens. (2019) 8:248. doi: 10.3390/pathogens8040248

9. Moreno E, Moriyon I. The Genus Brucella. In: Dworkin M, editor. The Procaryotes: An Evolving Microbiological Resource for the Microbiological Community. 3. New York, NY: Springer (2001). p. 315-457.

10. Mangtani P, Berry I, Beauvais W, Holt HR, Kulashri A, Bharti S, et al. The prevalence and risk factors for human Brucella species infection in a crosssectional survey of a rural population in Punjab, India. Trans $R$ Soc Trop Med Hyg. (2020) 114:255-63. doi: 10.1093/trstmh/trz133

11. Selim A, Attia K, Ramadan E, Hafez YM, Salman A. Seroprevalence and molecular characterization of Brucella species in naturally infected cattle and sheep. Prev Vet Med. (2019) 171:104756. doi: 10.1016/j.prevetmed.2019.104756

12. Saeed U, Ali S, Khan TM, El-Adawy H, Melzer F, Khan $\mathrm{AU}$, et al. Seroepidemiology and the molecular detection of animal brucellosis in Punjab, Pakistan. Microorganisms. (2019) 7:449. doi: 10.3390/microorganisms7100449

13. Nielsen K, Yu WL. Serological diagnosis of brucellosis. Prilozi. (2010) 31: 65-89.

14. Mathew C, Stokstad M, Johansen TB, Klevar S, Mdegela RH, Mwamengele G, et al. First isolation, identification, phenotypic and genotypic characterization of Brucella abortus biovar 3 from dairy cattle in Tanzania. BMC Vet Res. (2015) 11:1-9. doi: 10.1186/s12917-015-0476-8

15. Ulu-Kilic A, Metan G, Alp E. Clinical presentations and diagnosis of brucellosis. Recent Pat Antiinfect Drug Discov. (2013) 8:34-41. doi: 10.2174/1574891X11308010007

16. Kirk MD, Pires SM, Black RE, Caipo M, Crump JA, Devleesschauwer B, et al. World Health Organization estimates of the global and regional disease burden of 22 foodborne bacterial, protozoal, and viral diseases, 2010: a data synthesis. PLoS Med. (2015) 12:e1001921. doi: 10.1371/journal.pmed.1001921

17. Saddique A, Ali S, Akhter S, Khan I, Neubauer H, Melzer F, et al. Acute febrile illness caused by Brucella abortus infection in humans in Pakistan. Int J Environ Res Public Health. (2019) 16:4071. doi: 10.3390/ijerph16214071

18. Siyal GEA, Khalid I, Qaisrani A. Internal Migration and Urbanization: A Case Study from Semi-arid Regions of Pakistan. Islamabad: SDPI (2018).

19. Ishfaq S, Ahmed V, Hassan D, Javed A. In: Rajan SI. Internal Migration and Labour Mobility in Pakistan. Routledge Taylor \& Francis (2017).

20. Ismail M, Ahmad I, Khan MS, Ullah S, Malik MI, Muhammad $\mathrm{K}$, et al. Seroprevalance of Brucella abortus in cattle and buffaloes in district Rajanpur, Punjab, Pakistan. Pure Appl Biol. (2018) 7:556-64. doi: 10.19045/bspab.2018.70069

21. Ali S, Neubauer H, Melzer F, Khan I, Akhter S, Jamil T, et al. Molecular identification of bovine brucellosis causing organisms at selected private farms in Pothohar Plateau, Pakistan. Pakistan J Zool. (2017) 49:11114. doi: 10.17582/journal.pjz/2017.49.3.sc2

22. Soomro A, Kamboh AA, Rind R, Dawani P, Sarwar M, Abro SH, et al. A study on prevalence and risk factors of brucellosis in cattle and buffaloes in district Hyderabad, Pakistan. J Anim Health. (2014) 2:337. doi: 10.14737/journal.jahp/2014/2.3.33.37

23. Virtual Governance System, Livestock and Dairy Development Department. Avialble online at: http://www.livestockpunjab.gov.pk (accessed February 2020).

24. Probert WS, Schrader KN, Khuong NY, Bystrom SL, Graves MH. Real-time multiplex PCR assay for detection of Brucella spp., B. abortus, and B. melitensis. J Clin Microbiol. (2004) 42:1290-3. doi: 10.1128/JCM.42.3.1290-1293.2004

25. Hancock T, Jiang T, Li M, Tromp J. Lower bounds on learning decision lists and trees. Inform Comput. (1996) 126:114-22. doi: 10.1006/inco.1996.0040

26. Fountain-Jones NM, Machado G, Carver S, Packer C, Recamonde-Mendoza $\mathrm{M}, \mathrm{Craft} \mathrm{ME}$. How to make more from exposure data? An integrated machine learning pipeline to predict pathogen exposure. J Anim Ecol. (2019) 88:144761. doi: $10.1111 / 1365-2656.13076$

27. Mamani M, Majzoobi MM, Keramat F, Varmaghani N, Moghimbeigi A. Seroprevalence of brucellosis in butchers, veterinarians and slaughterhouse workers in Hamadan, Western Iran. J Res Health Sci. (2018) 18:e00406.

28. Godfroid J, Al Dahouk S, Pappas G, Roth F, Matope G, Muma J, et al. A "One Health" surveillance and control of brucellosis in developing countries: moving away from improvisation. Comp Immunol Microbiol Infect Dis. (2013) 36:8. doi: 10.1016/j.cimid.2012.09.001

29. Godfroid J. Brucellosis in livestock and wildlife: zoonotic diseases without pandemic potential in need of innovative one health approaches. Arch Public Health. (2017) 75:1-6. doi: 10.1186/s13690-017-0207-7

30. Musa MT, Eisa MZ, El Sanousi EM, Abdel Wahab MB, Perrett L. Brucellosis in camels (Camelus dromedarius) in Darfur, Western Sudan. J Comp Pathol. (2008) 138:151-5. doi: 10.1016/j.jppa.2007.10.005

31. Junqueira DG, Dorneles EM, Goncalves VS, Santana JA, Almeida VM, Nicolino RR, et al. Brucellosis in working equines of cattle farms from Minas Gerais State, Brazil. Prev Vet Med. (2015) 121:380-5. doi: 10.1016/j.prevetmed.2015.06.008

32. Jamil T, Melzer F, Khan I, Iqbal M, Saqib M, Hammad Hussain M, et al. Serological and molecular investigation of Brucella species in dogs in Pakistan. Pathogens. (2019) 8:294. doi: 10.3390/pathogens8040294

33. Khan AU, Sayour AE, Melzer F, El-Soally S, Elschner MC, Shell WS, et al. Seroprevalence and molecular identification of Brucella spp. in camels in Egypt. Microorganisms. (2020) 8:1035. doi: 10.3390/microorganisms8071035

34. Abubakar M, Mansoor M, Arshed M. Bovine brucellosis: old and new concepts with Pakistan perspective. Pak Vet J. (2012) 32:147-155.

35. Ali S, Akhter S, Neubauer H, Melzer F, Khan I, Ali Q, et al. Serological, cultural, and molecular evidence of Brucella infection in small ruminants in Pakistan. J Infect Dev Ctries. (2015) 9:470-5. doi: 10.3855/jidc.5110

36. Fatima S, Khan I, Nasir A, Younus M, Saqib M, Melzer F, et al. Serological, molecular detection and potential risk factors associated with camel brucellosis in Pakistan. Trop Anim Health Prod. (2016) 48:17118. doi: 10.1007/s11250-016-1148-9

37. Nielsen KH, Kelly L, Gall D, Nicoletti P, Kelly W. Improved competitive enzyme immunoassay for the diagnosis of bovine brucellosis. Vet Immunol Immunopathol. (1995) 46:285-91. doi: 10.1016/0165-2427(94)05361-U

38. Sanaei Dashti A, Karimi A, Javad V, Shiva F, Fallah F, Alaei MR, et al. ELISA cut-off point for the diagnosis of human brucellosis; a comparison with serum agglutination test. Iran J Med Sci. (2012) 37:9-14.

39. Godfroid J, Nielsen K, Saegerman C. Diagnosis of brucellosis in livestock and wildlife. Croat Med J. (2010) 51:296-305. doi: 10.3325/cmj.2010.51.296

40. Gul ST, Khan A, Ahmad M, Rizvi F, Shahzad A, Hussain I. Epidemiology of brucellosis at different livestock farms in the Punjab, Pakistan. Pak Vet J. (2015) 35:309-14.

41. Abubakar M, Javed Arshed M, Hussain M, Ehtishamul H, Ali Q. Serological evidence of Brucella abortus prevalence in Punjab province, Pakistan-a cross-sectional study. Transbound Emerg Dis. (2010) 57:4437. doi: 10.1111/j.1865-1682.2010.01171.x

42. Farooq U, Fatima Z, Afzal M, Anwar Z, Jahangir M. Sero-prevalence of brucellosis in bovines at farms under different management conditions. Brit J Dairy Sci. (2011) 2:35-9.

43. Ali S, Akhter S, Neubauer H, Melzer F, Khan I, Abatih EN, et al. Seroprevalence and risk factors associated with bovine 
brucellosis in the Potohar Plateau, Pakistan. BMC Res Notes. (2017) 10:73. doi: 10.1186/s13104-017-2394-2

44. El-Tras WF, Tayel AA, Eltholth MM, Guitian J. Brucella infection in fresh water fish: Evidence for natural infection of Nile catfish, Clarias gariepinus, with Brucella melitensis. Vet Microbiol. (2010) 141:321-5. doi: 10.1016/j.vetmic.2009.09.017

45. Madut NA, Muwonge A, Nasinyama GW, Muma JB, Godfroid J, Jubara AS, et al. The sero-prevalence of brucellosis in cattle and their herders in Bahr el Ghazal region, South Sudan. PLoS Negl Trop Dis. (2018) 12:e0006456. doi: 10.1371/journal.pntd.0006456

46. Renukaradhya GJ, Isloor S, Rajasekhar M. Epidemiology, zoonotic aspects, vaccination and control/eradication of brucellosis in India. Vet Microbiol. (2002) 90:183-95. doi: 10.1016/S0378-1135(02)00253-5

47. Ndengu M, Matope G, de Garine-Wichatitsky M, Tivapasi M, Scacchia M, Bonfini B, et al. Seroprevalence of brucellosis in cattle and selected wildlife species at selected livestock/wildlife interface areas of the Gonarezhou National Park, Zimbabwe. Prev Vet Med. (2017) 146:158-65. doi: 10.1016/j.prevetmed.2017.08.004

48. Ibrahim N, Belihu K, Lobago F, Bekana M. Sero-prevalence of bovine brucellosis and its risk factors in Jimma zone of Oromia Region, South-western Ethiopia. Trop Anim Health Prod. (2010) 42:35-40. doi: 10.1007/s11250-009-9382-z

49. Poester FP, Samartino LE, Santos RL. Pathogenesis and pathobiology of brucellosis in livestock. Rev Sci Tech. (2013) 32:105-15. doi: 10.20506/rst.32.1.2193

50. Yaeger MJ, Holler LD. Bacterial causes of bovine infertility and abortion. In: Robert S. Youngquist WRT, editors. Current Therapy in Large Animal Theriogenology. St. Louis, MO: Elsevier (2007). p. 389-99. doi: 10.1016/B978-072169323-1.50052-0

51. Ullah Q, Jamil H, Lodhi LA, Qureshi ZI, Ullah S, Jamil T, et al. Brucellosis is significantly associated with reproductive disorders in dairy cattle of Punjab, Pakistan. Pak J Zool. (2019) 51:1995-7. doi: 10.17582/journal.pjz/2019.51.5.sc10

52. Arif S, Thomson PC, Hernandez-Jover M, McGill DM, Warriach HM, Hayat K, et al. Bovine brucellosis in Pakistan; an analysis of engagement with risk factors in smallholder farmer settings. Vet Med Sci. (2019) 5:390401. doi: $10.1002 / \mathrm{vms} 3.165$

53. Arif S, Thomson PC, Hernandez-Jover M, McGill DM, Warriach HM, Heller J. Knowledge, attitudes and practices (KAP) relating to brucellosis in smallholder dairy farmers in two provinces in Pakistan. PLoS ONE. (2017) 12:e0173365. doi: 10.1371/journal.pone.0173365

54. Liu F, Wang D, Yang SC, Zhu JH, Li JM, Shi K, et al. Prevalence and risk factors of brucellosis, toxoplasmosis, and neosporosis among Yanbian Yellow cattle in Jilin province, China. Vector Borne Zoonotic Dis. (2019) 19:217-21. doi: 10.1089/vbz.2018.2288

55. Shabbir MZ, Nazir MM, Maqbool A, Lateef M, Shabbir MA, Ahmad A, et al. Seroprevalence of Neospora caninum and Brucella abortus in dairy cattle herds with high abortion rates. J Parasitol. (2011) 97:7402. doi: $10.1645 / \mathrm{GE}-2734.1$

56. Tesfaye G, Tsegaye W, Chanie M, Abinet F. Seroprevalence and associated risk factors of bovine brucellosis in Addis Ababa dairy farms. Trop Anim Health Prod. (2011) 43:1001-5. doi: 10.1007/s11250-0119798-0

57. Adugna KE, Agga GE, Zewde G. Seroepidemiological survey of bovine brucellosis in cattle under a traditional production system in western Ethiopia. Rev Sci Tech. (2013) 32:765-73. doi: 10.20506/rst.32. 2.2218

58. Musallam I, Ndour AP, Yempabou D, Ngong CC, Dzousse MF, Mouiche-Mouliom MM, et al. Brucellosis in dairy herds: a public health concern in the milk supply chains of West and Central Africa. Acta Trop. (2019) 197:105042. doi: 10.1016/j.actatropica.2019. 105042

Disclaimer: Frontiers Media SA remains neutral with regard to jurisdictional claims in published maps and institutional affiliations.

Conflict of Interest: The authors declare that the research was conducted in the absence of any commercial or financial relationships that could be construed as a potential conflict of interest.

Copyright (c) 2020 Khan, Melzer, Hendam, Sayour, Khan, Elschner, Younus, Ehtisham-ul-Haque, Waheed, Farooq, Ali, Neubauer and El-Adawy. This is an openaccess article distributed under the terms of the Creative Commons Attribution License (CC BY). The use, distribution or reproduction in other forums is permitted, provided the original author $(s)$ and the copyright owner(s) are credited and that the original publication in this journal is cited, in accordance with accepted academic practice. No use, distribution or reproduction is permitted which does not comply with these terms. 